\title{
Weakened Agents of Strategic Change: Negative Effects of M\&A Processeson Integration Managers
}

\author{
Svante Schriber ${ }^{1}$ \\ ${ }^{1}$ Department of Organization and Management, School of Business, Stockholm University, Stockholm, Sweden \\ Correspondence: Svante Schriber, School of Business, Stockholm University, 10691 Stockholm, Sweden. Tel: \\ 46-8-161-380. E-mail: svante.schriber@fek.su.se
}

Received: March 18, 2012 Accepted: May 4, 2012 Online Published: June 16, 2012

doi:10.5539/ijbm.v7n12p159 URL: http://dx.doi.org/ijbm.v7n12p159

\begin{abstract}
Traditional accounts of M\&A emphasize employees as victims of unintended negative effects of integration, resulting in poor motivation and productivity. In response, managers are seen as responsible for conducting integration while at the same time considering the well-being of employees. However, little research attention has been given the ability of integration managers to do so if they, too, suffer from low motivation and productivity. This study therefore asks how managers are affected by acquisition processes. Taking a structured approach to analyzing in-depth data from a Nordic acquisition it is shown that middle managers experience several negative effects of M\&A, however with some distinct features. Interpreted through the commonly applied theoretical lens, the negative effects on integration managers should reduce their ability to successfully lead integration, in turn contributing to explain the often poor performance of M\&A.
\end{abstract}

Keywords: merger, acquisition, strategic change, integration, management

\section{Introduction}

Mergers and acquisitions (M\&A) is a common growth strategy. M\&A offer several potential benefits such as reaching new markets (Lee and Lieberman, 2010), cross-selling, cost reductions through shared resources in logistics or production (Capron, 1999), or reaching new technologies and knowledge (Hagedornand Duysters, 2002). However, the organizational integration required to realize many benefits (Lubatkin, 1998, Sirower, 1997) has been found to be problematic (e.g. Shrivastava 1986), in turn giving rise to a broad research into the integration phase.

This research stream generally rests on two ideas. The first is that managers are responsible for driving integration. Even if employees have been found to contribute to integration (Greenberg and Guinan, 2004), managers generally are considered central in initiating and leading integration to realize synergy potentials (Shrivastava, 1986, Larsson and Finkelstein, 1999, Ranft and Lord, 2002).

The second idea is that although integration is necessary for taking advantage of potential synergies, but at the same time often has negative effects on employees. The organizational and psychological turbulence which often follows can cause stress, anxiety (Ivancevich et al., 1987, Napier, 1989), internal power struggles and politicking (Meyer and Altenborg, 2007). Further, integration can have negative impact on employee self-image (Vaara et al., 2005) and career opportunities (Piekkari et al., 2005). In sum, such effects have been found to be detrimental to employee morale, motivation, and productivity (Schweiger and Goulet, 2000).Consequently, managers are advised to balance the strive for synergies against the risk of negative employee reactions (Shrivastava, 1986, Haspeslagh and Jemison, 1991, Larsson and Finkelstein, 1999) and communicate honestly with employees throughout the acquisition process (van Dick et al., 2006, Kramer et al., 2004, Marks and Maris, 2001, Napier, 1989, Schweiger and Denisi, 1991).

By considering managers to be responsible for integration,researchhas left the questionunanswered how integrationprocesses affect managers. If managers are defined as employees with the role of leading other employees the thought model in integration literature should make this question central: if managers, too, suffer during integration, they should be less able to lead integrationor delimit its negative effects on other employees. So far, studies show increased turnover among target top managementafter M\&A (Krug and Hegarty, 1997, Lubatkin et al, 1999, Walsh, 1988), and have indicated negative experiences of middle management of the target firm (c.f. Fried et al., 1996). But as managers from the acquiring firm generally are expected to drive integration 
(Haspeslagh and Jemison, 1991), the lack of detailed accounts of personal experience of integration managers to $\mathrm{M} \& \mathrm{~A}$ - both in the acquiring and acquired firms - leaves research ill equipped to fully understand integration processes.

The purpose of this study therefore is to contribute to M\&A theory by exploring how integration managers perceive post-acquisition processes. This is done by a structured in-depth case study of a related acquisition. Thisis important for several reasons.Firstly, also managers should be included in the humanistic interest of how individuals are affected by M\&A(Hunt, 1990). Secondly, it adds insights to theories on integration processesthat still, despite years of research, largely remain enigmatic (e.g. Larsson and Finkelstein, 1999). Thirdly, as poor integration management has been a central explanation to reductions in productivity of employees in M\&A (Goldberg, 1983), increased understanding of theobstacles tomanagers can be a step towards explaining why M\&A so often lead to poor, or even negative, value creation (Datta, 1992, Moeller et al., 2005).

\section{Challenges to Successful M\&A Integration}

The degree or amount of integration required to realize synergies depends on the type of merger or acquisition. Integration in unrelated $M \& A$ offer limitedbenefits whereasrelated $M \& A$ might require tight integration to make use of economies of scale and scope (Haspeslagh and Jemison, 1991). M\&A involving high technological firms can require careful integration in some areas, yet leave others virtually unintegrated (Ranft and Lord, 2002, Schweizer, 2005).

With increasing research attention given to the human side of M\&A (Buono and Bowditch, 1989, Legare, 1993) the organizational turbulence that often is a consequence of integration has been found to cause a wide variety of negative effects for employees. A vast body of research shows that M\&A cause stress and anxiety among employees, primarily regarding the risk of losing one's job (Ivancevich et al., 1987, Napier, 1989). In addition, differences in national (Olie, 1994, Vaara, 1999) and corporate cultures (Larsson and Lubatkin, 2001) can lead to 'us versus them' sentiments, causing tensions between employees from the involved firms, in all reducing the chance of achieving integration (Schweiger and Goulet, 2000).

\subsection{A Framework for Employee Reactions to $M \& A$}

These findings on reactions among employees in M\&A are generated and anchored in various theoretical fields, thus adding well-founded and substantial theoretical insights to the empirically defined M\&A research field. However, insights thereby have remained fragmented within separate schools of thought. One effort to bring insights togetherand to create a more consistent knowledge base is offered by Seo and Hill (2005). Based on a thorough literature review six problematic areas to employees in integration processes are condensed, described, and explained, offering a structure for analyzing social effects of M\&A that should be applicable not only on employees, but also on managers.

\subsubsection{Increased Anxiety}

For middle managers, the announcement of a merger or an acquisition includes the risks of job loss. As merging two hierarchies into one includes having two applicants to every position, middle managers have been found to experience anxiety for their job security during M\&A processes (Piekkari et al., 2005). Added to the risk of losing one's own job, also losing long-time colleagues can cause anxiety (Napier, 1989). Given that M\&A are often negotiated secretly and information to others than top management is kept limited (Harwood, 2006), the first scarce news of M\&A open up to various interpretations and gossiping, in turn leading to furtheruncertainty, which can last during prolonged periods of time, adding to the psychological strain (Cartwright and Cooper, 1995).

\subsubsection{Changes in Social Identity}

Individuals typically draw upon group belonging in defining their own identity.M\&A by their very nature challenge existing work groups and units. Organizational changes therefore constitute a threat to the personal identity, often with a clearly negative connotation, leading to negative feelings being projected against integration and employees from the other firm (van Dick et al., 2006, Marks and Mirvis, 1985). For instance, studies of M\&A in professional service firms have shown that employees can feel the image of their own firm being contaminated by the merger with an organization considered less attractive (Vaara et al., 2003), making the own status seem reduced (Empson, 2000). Typically, employees react by attempting to position the own group against other groups, leading to jostling and conflicts (Haunschild et al., 1994).

\subsubsection{Acculturation Tensions}

Organizational cultures; ways of doing things and tacit basic assumptions (Schein, 1992), can remain unknown 
also to the members of a culture. The interaction with another organization forced by integration can cause unwanted challenges to the own culture, in turn leading to friction or even open clashes (Larsson and Lubatkin, 2001, Weber et al., 2011), especially when one culture is imposed on the other (Elsass and Veiga, 1994). How organizations deal with cultural tensions differs, from living separately, one firm adopting the culture of the other, to both blending (Nahavandi and Malekzadeh, 1988). It is often assumed that more similar cultures blend better, both when it comes to corporate (Weber, 1996) and national culture (Weber et al., 1996). But also initially similar cultures can grow apart as conflicting issues are attributed to culture, leading to a gradual and increasing construction of 'us' being different from 'them' (Vaara, 1999).

\subsubsection{Conflicting Roles}

As M\&A integration causesorganizational changes alsothe roles - the expected behavior of groups and individuals- can change, too (Rizzo et al., 1970). This has been found to be a source ofproblemsin integration processes (Ivancevich et al., 1987). New behavior can be required to manage incompatible demands between roles, such as remaining loyal to one's family when work changes in content and in amount, creating stress for the individual (Schweiger et al., 1987). For instance, owners of acquired family-owned firms can be forced to drastically change behaviortowards other employees when ownershipand hence loyalties change(Graebner, 2009).

\subsubsection{Changing Job Characteristics}

Even smaller changes than job loss can be perceived as negative. Managers often get extended responsibilities as a result of M\&A; for new markets (Homburg and Bucerius, 2006), products, or organizational resources (Meschi and Metais, 2006). Others face the risk of instead having reduced responsibilities. Changes in job characteristics and work content can be perceived very negatively (Buono and Bowditch, 1985). As integration typically involves changes in responsibilities, functions, new management systems (Shrivastava, 1986), or new reporting structures (Ranft and Lord, 2002), negative feelings of helplessness and being supervised can spread (Larsson, 1993).

\subsubsection{Perceived Injustice}

The changes in organizations that follow M\&A are not necessarily negative. But altering a status quo can open up both new and old conflicts, making many feel treated unfairly. Reductions in responsibilities, control over resources, or influence are often perceived as poorly grounded and without sufficient consideration to how the burdens are distributed (Choi et al., 2011). Also unfair treatment of colleagues can have detrimental effects on morale (Larsson and Finkelstein, 1999). Seemingly uniting efforts, such as the introduction of a common corporate language, can be unfair if employees from one firm generally master the corporate language better than employees from the other (Piekkari et al., 2005). Perhaps surprising, also an equal power between employees from the involved firms canlead to problems, as issues are not decisively handled, but instead risk leading to prolonged politicking (Meyer and Altenborg, 2007).

These six areas offer a broad and comprehensiveoverview of the problems relating to employees described in M\&A literature. Given the approach of this study and the width of the challenges which can appear in M\&A, the framework developed by Seo and Hill (2005) offers a good starting point for a structured analysis of the effects that M\&A processes can have on managers. In the following I turn to how this study has been designed to pave the way for that analysis.

\section{Methodology}

\subsection{Design of the Study}

The empirical study has been designed as an in-depthcase study (Yin, 2003) taking a process view of acquisitions (Jemison and Sitkin, 1986). In the necessary balance between number of cases and depth (Voss, 2002) the latter has been prioritized. In accordance with acknowledged case study methodology the case was selected using theoretical sampling (Eisenhardt and Graebner, 2007) to find data that is revelatory, interesting, and expected to contribute with important results (Eisenhardt, 1989). The chosen acquisition, representing a substantial deal in the Nordic food industry at the time, was considered suitable for several reasons. Firstly, the acquisition was clearly related and hence expected to require substantial organizational integration (Shelton, 1988). Secondly, involving around a thousand employees the acquisition allowed gathering sufficient data on integration efforts compared to acquisitions of relatively small firms (Shrivastava, 1987).

\subsection{Data Gathering}

Data gathering lasted around ten months. It started approximately four months after the public announcement of 
the acquisition, but was simultaneous with the main integration efforts, reducing the risk of interviewees forgetting or rationalizing. Interviewees represented both involved firms and all levels of the hierarchyand ranged from the $\mathrm{CEO}$ to team leaders and specialists.

Interviews were prepared using available public information. Later interviews also were prepared using earlier interviews to both guide questions to interesting areasand allowing triangulation (Jick, 1979). Interviews were semi structured following an interview guide covering both generic questions about the integration process and questions individually adapted to the interview person in order to increase the likelihood of collecting data well-known by each interviewee.

The 32 interviews lasted between 40 and 210 minutes, on average around one hour. Most interviews (26) were recorded. When the interviewee preferred not to be recorded notes were takenand summarized shortly after the interview.

\subsection{Data Analysis}

In line with suggestions to start with in-case analysis (Yin, 2003) all written data were summarized in a case description to create a contextual understanding of theacquisition. The data was then analyzed using computer a based tool (NVivo) supporting thematic analysis. This helped finding instances when managers described their own reactions, feelings, conflicts of interest, uncertainty and so on. Re-reading the surrounding text allowed structuring data according to certain topics and identifying common themes at the empirical level.Mixed with re-reading literature in an iterative manner typical to qualitative studies, instances both similar and different to previous findings and theories were identified.

In the following text the names from both firms are used to increase clarity, although the two firms after the acquisition officially were merged into one.

\section{The Acquisition}

\subsection{Background of the Acquisition}

Early in 2003Cerealia, owning Skogaholm acquired Schulstad. Cerealia thereby almost doubled its Swedish bakery capacity for fresh bread. Both Cerealia and Schulstad were present on the international arena with a wide range of products, e.g. frozen breads and biscuits, but the main synergistic motives for the acquisition were in the Swedish fresh-bread market.Skogaholm was the second largest supplier of fresh bread in Sweden. Schulstad, originally a Danish bakery company, had entered the Swedish market via an acquisition in 1999 and was the third largest producer. At the time, Skogaholm had around 550 employees in six bakeries and Schulstad four bakeries and around 400 employees. Together they closed in on, but did not overtake the market leader.

The acquisition took place in an industry characterized by overcapacity and strong pressure by customers, mainly three retail chains dominating the channels to customers. Well aware that Schulstad had grown aggressively and at a loss Skogaholm's CEO approached Schulstad's main owner. After long negotiations the deal was made public January 8, 2003. The Swedish Competition Authority gave its acceptance in April 2003, opening up for integration between the firms.

\subsection{Manager Perceptions of the Integration Process}

Managers from both Skogaholm and Schulstad were instrumental in driving the integration forward. Integration in several instances was rewarded with success. At the same time, managers often perceived the integration as stressful, negative, and sometimes outright painful.

\subsubsection{Anxiety - Fear of Job Loss, Lack of Information, and the Type of Acquisition}

There is clear evidence that several factors contributed to anxiety among managers in the joining firms. Managers at the top echelons in Schulstad received special compensation packages as a result of the deal and many left the firm soon after the acquisition. Managers outside of the top management in both firms faced a different situation. The most immediate concern to the interviewed managers was losing the own job, or that it would be subject to change as a result of the acquisition.

This was not least the case for managers in the target firm. Schulstad with a line organization was more or less fully integrated into Skogaholm, organized in three largely independent regional organizations. For former Schulstad employees this posed a threat. Having few, if any, former Schulstad supporters in top management and being unfamiliar with the new organizational structure many wondered where, if at all, they would be given a role in the merged firm. A marketing manager from Schulstad, remembering her first reaction when hearing about the acquisition: 
'Not knowing where you would fit into the other organization. And it did not come much information either. [...] The feeling was that top management in Schulstad would go. Everyone was afraid of losing his or her job. We expected rationalizations in the organization and knew that it would be very difficult to get a position in the new organization, similar to the existing Skogaholm organization.'

For almost every management position there were two applicants, one from each firm, with largely the same background and competences. This paved the way for hopes, but also for uncertainty, competition, and politicking. Despite this, many were forced to work together for several months, knowing that only one would be offered a job. A manager in marketing, originally from Skogaholm, describes this slightly absurd situation:

'In the acquisition there was an equivalent counterpart [in Schulstad], and that is the way it is; it is something unpleasant in situations like this. And you sit with your colleague and both know that "one of us is going". It is a situation of eating or being eaten.'

The lingering uncertainty had several consequences. One was that productivity in many instances decreased dramatically. Personal commitment wavered as the future of both the own career and on-going projects became more uncertain. By June 2003 it was clear that Skogaholm's structure would prevail and dismissals began. But the actual turnover was higher than that: as soon as the first decisions regarding the structure and future strategy trickled down from top management several middle managers from Schulstad predicted the way things were going. Not least the fact that Schulstad's head office was located in Gothenburg, some 500 kilometers from Skogaholm's head office in Stockholm, reduced the chance of staying on a high managerial position without moving. Many took the consequence. An administrative manager from Skogaholm: 'Many of these managers from Schulstad quit voluntarily, because they saw the direction things were taking'. This in turn left partly unfamiliar tasks and an increase in workload for those who stayed. A production manager fills in: 'When the deal was announced great anxiety spread, of course. A lot of people who would have been given notice if they had stayed on quit their jobs. It was turbulent.'

The uncertainty also made employees leave voluntarily. Many perceived the time between the announcement and acceptance from antitrust authorities as a long period of waiting. Lacking information employees - including managers - started speculating and gossiping. Also in the acquiring firm, Skogaholm, sentiments were mixed between uncertainty and fear. Seeing several Schulstad employees leaving the firm caused uneasiness - what if that was the smart thing to do? An administrative manager in Skogaholm describes: 'When the deal was signed a major uneasiness spread. A lot of people quit; it was turbulent.' A Schulstad marketing manager describes how lack of information added with increased turnover led to lack of momentum, further confusion, and that projects slowed down:

'It led to speculations and inefficiencies. At the same time colleagues left, adding to the confusion. I have been in integration processes before, and it is my experience that there always is too little information, making everything sort of stop.'

As indicated in the quotes above, one source of concern was the uncertainty what would happen, fuelled by lack of information. Most managers were informed when the acquisition was announced publicly. Many heard about the merger via official channels; receiving an e-mail, by reading about it on the pin wall or on the company intranet. Others were informed in large meetings. But most interviewed managers heard about it from their own superiors. This was perceived as by far the best way - especially not being surprised by hearing about it in TV or radio. A production manager in Skogaholm remembers: 'I heard the news from my manager. I don't remember the details, but I was informed before hearing about it in media'. As news spread, information reached also those not currently in their regular workplace. A marketing manager in Schulstad heard about the acquisition during the annual kick-off for Schulstad's marketing department at an external conference site. She remembers:

'The second day the Marketing and Sales Manager told us "We have been acquired". People were quite shocked; we had not heard of any negotiations. Even if we knew that Schulstad's finances were bad it was discomforting when it became concrete in that way.'

If the acquisition was kept a secret to most employees, some suspected that something was about to happen. Behavior among top management deviating from what was perceived as normal was interpreted as an early warning of something. In particular, decisions normally taken quickly suddenly appeared to be difficult and worthy of lengthy consideration. A bakery manager remembers that the acquisition announcement suddenly explained odd behavior regarding routine investments: 'Then you understood why you got the answers you did and why certain issues were handled a certain way'.

The lack of information in combination with fears, in particular of job loss, led to rumors. One held that 
Skogaholm secretly aimed at running Schulstad into bankruptcy, thereby being able to re-hire some employees rather than being restricted by labor laws regulating dismissals. A Skogaholm manager recalls:

'I have heard later that [Schulstad employees] were convinced that we bought them to put them into bankruptcy. That is what they believed. And that we then would buy it back, having more freedom which people to keep and to what conditions.'

Given the history of low profit levels in the bakery industry several interviewees had anticipated a restructuring in the industry. Some, mainly Schulstad employees, saw the possibility of acquiring Skogaholm as a logical extension of Schulstad's previous aggressive growth. When the reverse was announced Schulstad employees were surprised, shocked, and often negative. The marketing manager has a clear memory of her perception of the response at the conference site: 'Reactions were negative'. She continues: 'It took a long time before we heard anything [more]. No information came and everything sort of died.'

However, this reaction of uncertainty and anxiety that dominates the data can be contrasted with other views. Another Schulstad manager admits also having fears, but mainly seeing the acquisition as a possibility:

'I thought it sounded exciting! I might be a bit weird, but I saw this as an opportunity. Of course you also start thinking; there were no guarantees to be offered to stay on, I didn't know what would happen to my brand, and so on. And the organization was not settled, who would do what? But Schulstad had struggled [financially] a long time. I thought something had to happen, and this was an opportunity.'

But this was the exception and it should come as no surprise that being taken over in a horizontal acquisition in a crisis ridden industry was met mainly with negative sentiments in Schulstad. In sum, managers outside of top management received the information at the time of the announcement but received little information after that. Reactions were highly personal and diverging but the most common reaction was one mirroring the expected negative consequences for the own job not least because of the large overlaps between the two firms.

\subsubsection{Changes in Social Identity - Becoming 'Duller' in Skogaholm}

The most significant change in organizational identity took place in Schulstad. Many Schulstad employees were proud of the rapid growth preceding the acquisition. They viewed Schulstad as the modern alternative, embracing new management ideas: a matrix organization, trendy advertising in television, computer based planning systems, and outsourcing for instance of trucks and IT services instead of owning them - all contrasting against Skogaholm.This more modern image was reflected even in the product range, building heavily on full-grain and healthier breads directly targeting a young, urban customer base. Some also interpreted Schulstad's financial performance this way: even if results were negative the reason was the rapid expansion, and they would soon turn profitable. Even the acquisition fitted this picture when interpreted as a means of Skogaholm neutralizing a successful contestant. A production planning manager in Schulstad explains their success, exemplifying by recently becoming preferred supplier in two customer retail chains:

'We were on the way [of overtaking Skogaholm]! Axfood had kicked out Skogaholm and chosen us as bread supplier instead before the acquisition. And we were on the verge of kicking Skogaholm out of ICA, too. And about that time the acquisition was made public, that Skogaholm acquired us; a dangerous competitor.'

To others, however, the acquisition was a confirmation that things had not been managed correctly. Some - also former Skogaholm employees - saw Skogaholm as old-fashioned and slightly dull, economical, and lacking in fantasy, but profitable. As Schulstad had lived above its resources the acquisition was a call back to reality. But remedies to profit problems created further problems. A technical manager in Schulstad gives his view on the performance, both tracing it to the period before Schulstad entered the Swedish market, and pointing to lack of stability as a cause of problems:

'I believe an important factor is that this firm performed badly before Schulstad acquired it. Schulstad comes in to make it profitable and failed completely, economically speaking. It [Schulstad] is practically bankrupt. And then Skogaholm enters and aims at improving things. That creates uncertainty, there is no stability, there are changes all of the time. People do not feel safe.'

In addition to not being familiar with the new organization and lacking support from own managers, former Schulstad managers faced other problems. Often with a background in other industries and with higher formal education, the salary levels were higher than their peers from Skogaholm. An administrative manager in Skogaholm recalls: 'They were of another caliber, maybe not in terms of skills but they had come further in life, so to speak, and they earned much more. There was no willingness to pay that much, and they were not willing to reduce their salaries to the levels of ones like myself.' The identity of many Schulstad employees changed as their previous situation; working in a growing firm with high ambitions and high salaries, both changed by the 
acquisition.

\subsubsection{Cultural Tensions - Different Ways of Working}

Also cultural differences between the two firms were a recurring topic in interviews. Ways of working, routines, and methods, in turn imprinted in technical solutions, but also tacit differences existed differed between the firms. In the stressful situation also seemingly small differences could create friction in integration. An example was the distribution organization; how various types of products; loafs, buns, and sliced breads, were assembled according to customer orders. Even if the result was the same, the process differed between the two firms, leading to arguments about which way was the best. Tensions arose on the warehouse floors when teams from the two firms were integrated, forcing managers to try to alleviate stress and create understanding between the two organizations. A sales manager from former Skogaholm explains: 'I have to make sure the district managers have understanding for the other firm. Then you understand why you do things this way or that. So the guys loading customer orders understand this.'

Despite both firms being Swedish some interviewees pointed to national culture as a problem. Even if Skogaholm managers perceived themselves as straightforward and direct, they reacted against a culture which they attributed to Schulstad's origin. Schulstad management methods thatwere perceived as clearly Danish: stricter hierarchies, a higher degree of open conflict, paired with a 'hire and fire' culture. A bakery manager from former Skogaholm recognized the challenge also from Schulstad's point of view: 'There definitely were cultural clashes. Schulstad had gone through a tough period since the Danes took over and implemented a Danish philosophy. And then adjusting back again to us; of course it is a challenge.'

Differences also were attributed to corporate culture. The contrast can be illustrated by Skogaholm managers seeing Schulstad as more modern, college graduates, but also overemphasizing theoretical discussions, and being too fond of meetings and committees. The contrast to the simpler, more straightforward Skogaholm was highlighted in many interviews such as this, with a production manager in Skogaholm:

'Skogaholm has always been a bit more "This is what we'll do, chop-chop, let's go!" whereas Schulstad liked to have long investigations. And meetings, meetings, meetings! So when we barged in and said "Now this is going to happen on Monday!" they got all confused. "But, we cannot do that!" and we went "Yes, let's go!" It was a real culture shock.'

Thus, the perceived differences between the two firms were attributed to both national and corporate cultures and touched on both the daily operations and the managerial work. Interestingly, the national culture was intertwined in the management culture, where both emphasis on hierarchy and having many meetings was perceived as 'Danish', even if the vast majority of the employees were Swedish.

\subsubsection{Role Conflict - Being Forced to Fire People, Not Being Able to Inform}

Almost all managers express acceptance that extraordinary times required extraordinary measures. Working overtime was seen as natural. But in some interviews the conflicting demand between work and private roles comes to surface. An administrative manager from Skogaholm, recently having become a father, experienced tensions between his professional and private roles. After several months of working overtime, tolerance from his family was wearing thin: 'I became father in July last year [2003] and I haven't been able to spend much time at home. So there is friction at home, too, when they say: "You could be at home at least occasionally".'

But perhaps the strongest sense of conflicting roles related to reductions. Firing others represented the opposite to the role of being a good manager; growing the firm, and helping subordinates to contribute to the firm. On a more personal level, several managers expressed their sadness over being forced to give notice to employees, some of which they had known and worked with for years.

A standard compensation of 8000 Swedish Krona [approximately 1000 USD] was offered to those who lost their jobs, a sum recognized by many managers as virtually nothing. Most managers mention their efforts of softening the blow by telling the employee personally. One manager in Skogaholm pensively describes the type of situation he was facing at the closing of a bakery in Gothenburg:

'I can tell you - that was not a fun day. I did it all in one day, to have it over and done with. It was not fun, no, it was not. [...] There was a guy working half time, he had worked in the bakery and got stuck with an arm in a machine, so he only could use one arm. So he said with tears in his eyes: "I will never be able to find a job again." He was 51 years, part time retired, with one healthy arm.'

A bakery manager points to the deeply personal side of firing employees, with feelings on the verge of betrayal when closing Skogaholm's bakery in Gothenburg and not being able to hold the promise when hiring staff: 'I had 
hired most of the people I had to fire.' Also other circumstances mattered. That same manager also was involved in closing another bakery. It was much smaller and with a less automatized and more old-fashioned production line, requiring more craftsmanship from employees. On the one hand, employees knew that it was not efficient and some anticipated the closing. On the other, the small scale of operations made this decision more emotional. He describes almost nostalgically:

'It was intimate, a small town bakery. I think that is the term - I cannot say I know another bakery quite the same. I have seen similar tendencies in other small firms in a small town: it becomes more an integrated part of life, with a very high sense of unity, and another attitude towards work.'

But also other, less dramatic instances caused a feeling of insufficiency. Managers were well aware of the need to inform employees. One regional manager from Skogaholm neatly summarizes what also has been concluded in M\&A research, such as the importance of continuously informing even when nothing has happened, yet an inability to provide sufficient information:

'Of course you have to keep co-workers and employees as informed as possible. [...] After the signing there was a total silence. Then you have to start informing. "Now we have applied to the Antitrust Authority". "Now nothing happens". Of course you try to keep people informed. But I believe that people always experience a need for more information. You rarely hear anyone having had too much information.'

However, on the whole, this insight was not always matched by deeds. It took from January until September before the actual integration efforts started, a period characterized by uncertainty about the organization structure, about appointments, strategy and product ranges. One of the regional managers describes: 'It was frustration and uncertainty during the time before we got acceptance from the Antitrust Authorities. It took almost six months before we could start making decisions'. Thus, much of the information asked for by employees depended on decisions not yet made, making the first six months a period of missing information, to employees and managers alike. In sum, therefore, managers experienced feelings of insufficiency by being drawn between conflicting roles, most clearly visible when forced to implement reductions.

\subsubsection{Change in Job Characteristics - Mainly Reduced Influence}

Also those who kept their jobs often found themselves in changing circumstances as a consequence of the acquisitions. Some were optimistic. For individual managers integration could have different effects on the area of responsibility. A new position opening up to a new career could be offered without much ado. A manager from Schulstad being offered the position of bakery manager describes her manager saying "'I'm going to offer you this job, would you like it?", "'Yes, thank you, of course.” That was it.'

The majority, however, was more concerned. Managers from Schulstad who were offered a new job realized that it would be under new conditions compared to the situation before the acquisition. As mentioned insection 4.1Schulstad's central headquarter was located in Gothenburg, Sweden, in one of Skogaholm's three market regions. For employees in Schulstad this created the uncertainty whether their competences would be matched against the needs on national level, i.e. against available roles at Skogaholm's head quarter in Stockholm, or if they would be considered something for the regional head office to deal with. A brand manager remembers the sense of uncertainty:

'The feeling was that all our knowledge and systems were of a different kind compared to what was needed in the new firm. And it was difficult integrating into three [regional] organizations where the obvious question was: are we integrated into Market Region South or into Stockholm? There was a lot of uncertainty already there.'

Integration, making Schulstad managers redundant or leave voluntarily, gradually shifted much of the decision making to Skogaholm. Employees used to playing important roles in Schulstad organization experienced the shift as a gradual loss of influence, and increasing uncertainty. One production manager saw his responsibilities diminish as a result of the acquisition:

'I was the coordinator for all products, prognoses, new product launches and things like that; gathered and spread the information everyone needed. And now, I don't know, these natural channels and communication points do not exist anymore. It's not clear who is to have this information and who is to pass it on?

Interview data also reveals close emotional connections with work tasks. Following the acquisition, efforts were made to reduce the risk of cannibalization by weeding out products considered too similar. Marketing managers saw the risk that years of hard work suddenly could be to no avail for their career. Also a personal tie to the brand appears, as in this quote by a marketing manager: 'I did not know what would happen to my brand, and all our projects just stopped. A lot of energy went into thinking about that.' In sum, many managers perceived a reduced level of influence as a consequence of the integration, creating both uncertainty and uneasiness. 


\subsubsection{Not Perceived Injustice - But Increase in Work Load}

Even if many managers saw their roles change, risked job loss, and experienced colleagues leaving or being given notice, interview accounts offer few instances expressing perceptions of injustice. In most accounts the negative effects of integration appear to be taken with a matter-of-fact approach: reductions were unpleasant, but forced by the circumstances.

However, an issue of concern to many managers was the mounting hours of work needed to integrate the firms. In all functions of the firms the everyday operations had to continue. This means that integration efforts had to be added to the normal hours of work. The administrative manager in Skogaholm recently having had a child was overwhelmed by the integration workload he had to manage. Seemingly petty details took longer than expected. For instance, the change in Schulstad's organizational registration number also changed the subscription with the telecom provider. This had the consequence that several phones previously billed together suddenly were billed separately. 'So I had to sit down and open 50 envelopes and figure out: "Now who is this? Should his or her subscription be terminated?" Given the turbulence the manager was hesitant to terminate too many telephone subscriptions, as a non-functioning phone could be interpreted as the first step towards being fired. The care that was required meant more work. 'It has been an extreme lot of work. I had not expected it to be this much work. I never could imagine it to be this much work!' Also production managers suffered. A bakery manager sarcastically laughed at the question of what she, given the chance, would have done differently in integration, answering 'taking the Christmas off'. She added 'We have been in a hurry in everything we do. We live on the verge of panic all the time.'

Feelings of frustration about fatigue from working hard over long periods and lack of time appear clearly in data. But also more tangible medical effects appeared, as witnessed by a marketing manager:

'It has cost very much, and it catches us up now, unfortunately, but the organization is tired, incredibly tired. We are all tired. It has required such an enormous effort to work 70-80 hour weeks since August [until May, 2004]. And somewhere it doesn't work anymore. And we see that now; people on the verge of breaking down. One of my colleagues has had a burnout [i.e. medically prescribed not to work].'

In sum, few perceptions of injustice appear in data. The integration process however required that middle managers in both firms worked overtime, often doubling the workload. This was accepted but had negative consequences over time.

\section{Discussion}

M\&A can offer opportunities to grow faster, with less risk, compared to other growth strategies, in turn making M\&A a common feature in business in virtually all developed economies. However, their prevalence is not matched with success: empirical research repeatedly has pointed to poor or even negative outcomes, often explained by failure by managers to sufficiently handle the challenges during the integration phase. This study built on two ideas central to M\&A literature: that managers are responsible for integration, and that employees often suffer, with poor motivation and performance as a result. Against this background the current study set out to make an in-depth and structured analysis of how integration managers perceive post-acquisition processes. More specifically, a substantial acquisition in the Swedish bakery industry was studied using a framework developed by Seo and Hill (2005) summarizing the effects which M\&A have on employees. This allows drawing some important conclusions.

At an overall level data supports that managers in M\&A suffer much the same types of problems as employees in general. Anxiety was a common reaction to the announcement of the acquisition, similar to findings regarding reactions of other employees. The fear of losing one's job was widespread in both firms, but appeared more clearly in the target company. A lack of information from top management once integration started added to the uncertainty and anxiety (Ivancevich et al., 1987).

More interestingly, problems appear as connected specifically to the manager role during the integration process. The social identity of managers changed, predominantly in the target firm. The previous perception of being trendy changed gradually with integration, but the feeling of being successful changed dramatically once the acquisition was announced. Also cultural tensions were evident. In accordance with theory (Schein, 1992) differences in basic assumptions made cooperation with new colleagues from the other firm difficult and communication only partly successful as means of reducing the tension (Weber et al., 2011). Interestingly, however, perceptions of corporate and national cultures were intertwined. The consequence was a mix between perceptions of typically Danish traits, such as strict hierarchies, but lacking elements of strict top-down decision-making, instead replaced with 'meetings, meeting, meetings', arguably more related to a professional 
culture (Empson 2000) in Schulstad. This suggests that cultural traits might interact, and supports the view of culture as a phenomenon more complex than often described in M\&A literature (Vaara 1999).

A further source of negative experience was the feeling of role conflict; being prevented by the acquisition from living up to own perceptions of what it means to be a good manager. Data indicates that managers indeed knew the importance that they informed their subordinates about the acquisition (e.g. Kramer et al., 2004). However, stronger than in existing literature appears the frustration among managers of being unable to inform because managers themselves lacked information. Even stronger were the feelings when having to give notice to people who in many cases had worked loyally over the years and in some instances had been hired by that same manager. Interview accounts reveal feelings of failure and betrayal. This is an important result in relation to the existing understanding of integration processes.

Also the feeling of conflicting private and professional roles was perceived as negative, such as when integration work over months reduced the time which could be spent with family, thus overlapping with findings in earlier studies (Schweiger et al., 1987). Even if some managers benefited from the acquisition such as through new and expanded areas of responsibility, many saw their roles reduced, changed, or made more insignificant as a result of the acquisition. This was particularly significant in the target, as its firm structure was adapted to the acquirer, thereby forcing one matrix organization into three regional but traditional hierarchies, making job characteristics dramatically different.

If the data overlaps with five of the categories suggested by Seo and Hill (2008), a sixth offers a slightly different view. Interview accounts did not express perceptions of unfairness, not even in the target firm. This is somewhat surprising given that Schulstad employees were more likely for instance to lose their job, feel that the acquisition 'contaminated' their own self-image (Empson, 2000) and that signs of politicking were visible (Meyer and Altenborg, 2007). A potential explanation is that circumstances were accepted: the industry as a whole was under pressure, reductions had been ongoing for years and in both firms. Maybe the fact that the acquisition was an expected extension of this logic reduced the sense of injustice. A possible interpretation of this result then is that reductions in M\&A taking place in industries under price pressure might be perceived as less unjust, compared to reductions which come more as a surprise, such as in expanding industries. This nuances earlier findings that employee resistance is higher in related than unrelated M\&A (Larsson and Finkelstein, 1999), suggesting that also expectations relating to the industry situation influence employee reactions.

If little support is found for the notion that integration was conducted unfairly or perceived that way an additional factor not included by Seo and Hill (2005), nor given much notice in other integration literature, stands out in data and can be added as a seventh category. This refers to the workload that came with the integration. There is abundant support in data that the workload related to integration added to day-to-day business was a tangible burden arguably more so for managers than other groups of employees. Responsibility both for important decisions and seemingly petty tasks involved analyzing, initiating, delegating, controlling, and supervising integration, often doubling the workload. Expressing loyalty to the situation in most situations, some managers pointed to the strain on the organization, and colleagues experiencing exhaustion or even burnouts, especially in the long run. Taken together, findings indicate that managers indeed suffer many problems similar to employees, but that others are more accentuated for or even limited to the management function.

The framework by Seo and Hill (2005) was applied as it offers a structured means of analyzing effects of M\&A on managers, distinctly separating the six problems which have been found to occur. The analytical benefits however risk hiding that problems appear as anything but distinct. Instead, the negative effects appeared intertwined and complex. For instance, changes in ways of working, altering the job characteristics of several managers (Buono and Bowditch, 1985) also implied changes in the culture, i.e. in the methods applied to certain problems and how everyday work was dealt with (Schein, 1992). Work overload created conflicting roles, such as between private and professional roles. This implies that to the extent to which managers are experiencing several of these issues the effects are likely to add up in a cocktail of negative employee-related integration effects, potentially exceeding the sum of its parts; a form of 'negative social synergies'.

In addition, the aim of this study was to contribute to M\&A literature by focusing a layer in the managerial hierarchy previously often overlooked. Results, however, should not be seen in isolation. Instead, the organizational processes that developed included not only the effects on managers, but also the interaction effects with employees. In such a multi-layered view, the challenges facing managers appear as even more complex. For instance, information is one of the most common remedies prescribed in M\&A integration literature (Ivancevich et al., 1987, Marks and Mirvis, 1998, Risberg, 2003, Schweiger and Goulet, 2000, Schweiger and Walsh, 1990). It is clear that managers were aware of this and attempted to inform when possible, 
but that this often did not help. Three explanations stand out. Firstly, managers lacked information to give (Risberg 2003) as the process delayed decisions, in turn making it difficult to give substantial information to others. Secondly, even when this was possible, mistrust, and suspicion that the real integration plans were hidden not to cause more anxiety, paradoxically gave rise to worrying, speculation, gossiping, and more anxiety.

Thirdly, formal integration was up against a difficult situation. Being a horizontal acquisition many interviewees expected much of the synergies to have a negative impact on large parts of the organizations (e.g. Napier, 1989). And rightly so: reductions took place along all of the value chain: from administration via production, marketing, and logistics. As indicated by Larsson and Finkelstein (1999) M\&A between largely similar firms lead to more negative employee reactions, as they are associated with cost synergies, and reductions. This suggests that the task for managers were more difficult compared to $M \& A$ requiring less integration and reductions.

To conclude, data shows that managers suffer largely the same negative experiences of M\&A as do other employees, but arguably even more so because of the added strain of increased feelings of insufficiency and role conflict, and an often doubled workload. As was argued in the introduction, one of the fundamental ideas in integration literature is that employees who suffer anxiety and uncertainty during integration are less motivated and that this is an important explanation to why M\&A fail (Napier 1989). Interpreted through the integration literature lens, the negative impact on middle managers, responsible for integration (e.g. Larsson and Finkelstein, 1999), should lead to lowered motivation in integration (Ivancevich et al., 1987), and lowered performance (Goldberg, 1983, Larsson and Finkelstein, 1999). This should have two consequences: reduced ability both to realize synergies (Ranft and Lord, 2002), and to consider the well-being of other employees.

Middle managers thereby risk becoming weakened in their ability to implement the strategic change that M\&A constitute. Put slightly differently, if middle managers are seen as the main 'tool' for driving integration, these findings indicate that it risks becoming more 'blunt' by the very integration process they are supposed to manage. This in turn suggests a potentially self-reinforcing dynamism: poor integration management having negative consequences, in turn would make later integration efforts even poorer, and so on. In itself this result thereby adds to insights from earlier integration studies (e.g. Schweiger and Goulet, 2000). More importantly it appears as an important factor contributing to explaining the often reported poor performance of M\&A (Datta, 1992, King et al., 2004, Moeller et al., 2005).

The basic implication for practitioners is that to the extent that the managerial function has negative experiences of the M\&A process it is less likely to be able to perform its integration duties successfully. Allowing information to flow early and freely across managerial levels to reduce uncertainty, to prepare managers psychologically that they might perceive their roles as managers differently during integration, but foremost to make explicit efforts to reduce their workload, are efforts likely to increase the chance of success in M\&A.

The present study has been conducted in one related acquisition in a traditional industry. Apart from building only on one case, it is worth commenting on the validity of the study. Data gathering was directed towards integration efforts, rather than the negative impact of the integration process on integration managers. As these negative effects appeared inductively, without specifically being asked for, a careful guess could be that negative effects were a problem perceived as very real. Potentially more, and other, issues would appear using more directed data gathering. Thus, much remains to be done in expanding the view of managers in acquisition processes. This suggests taking a broader approach in future studies of managerial reactions e.g.in unrelated acquisitions and involving firms in other industries.

\section{References}

Anette R. (2003). The Merger and Acquisition Process. Retrieved from http://www.google.com.hk/url?sa=t\&rct=j\&q=The+Merger+and+Acquisition+Process. + Journal + of + Interna tional+Business + Literature + Review $\% 2$ C\&source $=$ web $\& c d=1 \&$ ved $=0$ CF 4 QFjAA\&url $=$ http $\% 3 \mathrm{~A} \% 2 \mathrm{~F} \% 2 \mathrm{Fc}$ iteseerx.ist.psu.edu\%2Fviewdoc\%2Fdownload\%3Fdoi\%3D10.1.1.198.1560\%26rep\%3Drep1\%26type\%3D pdf\&ei=vgu7T-PwEsmUiAfu7fDqCA\&usg=AFQjCNEaIuVFB8Yxbvfv39RkvbzNabRzmg\&cad=rjt

Buono A. F., \& Bowditch J. L. (1989). The Human Side of Mergers and Acquisitions. San Francisco: Jossey-Bass.

Buono A. F., L. J. B., \& Lewis J. W. I. (1985). When Cultures Collide: The Anatomy of a Merger. Human Relations, 38, 477-500. http://dx.doi.org/10.1177/001872678503800506

Capron L. (1999). The long-term performance of horizontal acquisitions. Strategic Management Journal, 20, 987-1018. http://dx.doi.org/10.1002/(SICI)1097-0266(199911)20:11<987::AID-SMJ61>3.0.CO;2-B

Cartwright S., \& Cooper C. L. (1995). Organizational Marriage: "Hard" Versus "Soft" Issues? Personnel Review, 


\section{4, 32-42. http://dx.doi.org/10.1108/00483489510089632}

Choi S., Holmberg I., Löwstedt J., \& Brommels M. (2011). Executive management in radical change--The case of the Karolinska University Hospital merger. Scandinavian Journal of Management, 27, 11-23. http://dx.doi.org/10.1016/j.scaman.2010.08.002

Datta, D. K., Pinches, G. E., \& Narayanan, V. K. (1992). Factors Influencing Wealth Creation from Mergers and Acquisitions: A Meta-Analysis. Strategic Management Journal, 13, 67-84. http://dx.doi.org/10.1002/smj.4250130106

Eisenhardt K. M., \& Graebner M. (2007). Theory Building from Cases: Opportunities and Challenges. Academy of Management Journal, 50, 25-32. http://dx.doi.org/10.5465/AMJ.2007.24160888

Eisenhardt, K. M. (1989). Building Theories from Case Study Research. Academy of Management Review, 14, 532-550. http://dx.doi.org/10.2307/258557

Elsass P. M., \& Veiga J. F. (1994). Acculturation in Acquired Organizations: A Force-Field Perspective. Human Relations, 47, 431-454. http://dx.doi.org/10.1177/001872679404700404

Empson, L. (2000). Mergers between Professional Service Firms: Exploring an Undirected Process of Integration. In C. L. Cooper, \& A. Gregory (Eds.), Advances in Mergers and Acquisitions (pp. 205-237). Amsterdam: JAI.

Fried Y., Tiegs R. B., Naughton T. J., \& Ashforth B. E. (1996). Managers' reactions to a corporate acquisition: A test of an integrative model. Journal of Organizational Behavior, 17, 401-427. http://dx.doi.org/10.1002/(SICI)1099-1379(199609)17:5<401::AID-JOB774>3.0.CO;2-R

Goldberg W. H. (1983). Mergers: Motives, Modes, Methods. New York: Nichols Publishing Company.

Graebner M. (2009). Caveat Vendor: Trust Asymmetries in Acquisitions of Entrepreneurial Firms. Academy of management Journal, 52, 435-472. http://dx.doi.org/10.5465/AMJ.2009.41330413

Graebner, M. E. (2004). Momentum and Serendipity: How Acquired Leaders Create Value in the Integration of Technology Firms. Strategic Management Journal, 25, 751-777. http://dx.doi.org/10.1002/smj.419

Greenberg, D., \& Guinan P. J. (2004). Mergers and Acquisitions in Technology-Intensive Industries: The Emergent Process of Knowledge Transfer. In Pablo, A. L., \& Javidan, M. (Eds.), Mergers and Acquisitions, Creating Integrative Knowledge (pp. 135-155). Malden, MA: Blackwell Publishing Ltd.

Hagedorn J., \& Duysters G. (2002). External Sources of Innovative Capabilities: The Preference For Strategic Alliances or Mergers and Acquisitions. Journal of Management Studies, 39, 167-188. http://dx.doi.org/10.1111/1467-6486.00287

Harwood, I. (2006). Confidentiality Constraints within Mergers and Acquisitions: Gaining Insights through a "Bubble" Metaphor. British Journal of Management, 17, 347-359. http://dx.doi.org/10.1111/j.1467-8551.2005.00440.x

Haspeslagh, P. C., \& Jemison D. B. (1991). Managing Acquisitions: Creating Value through Corporate Renewal. New York: Free Press.

Haunschild P. R. (1994). How Much Is That Company Worth? Interorganizational Relationships, Uncertainty, and Acquisition Premiums. Administrative Science Quarterly, 39, 391-411. http://dx.doi.org/10.2307/2393296

Homburg C., \& Bucerius M. (2006). Is Speed of Integration Really A Success Factor of Mergers and Acquisitions? An Analysis of the Role of Internal and External Relatedness. Strategic Management Journal, 27, 347-367. http://dx.doi.org/10.1002/smj.520

Hunt, J. W., \& Downing, S. (1990). Mergers, Acquisitions and Human Resource Management. International Journal of Human Resource Management, 1, 195-209. http://dx.doi.org/10.1080/09585199000000047

Invancevich, J. M., Schweiger, D. M., \& Power, F. R. (1987). Strategies for Managing Human Resources during Mergers and Acquisitions. Human Resource Planning, 10, 19-35.

Jick T, D. (1979). Mixing Qualitative and Quantitative Methods: Triangulation in Action. Administrative Science Quarterly, 24, 602-611. http://dx.doi.org/10.2307/2392366

King D. R., Dalton D. R., Daily C. M., \& Covin J. G. (2004). Meta-Analyses of Post-Acquisition Performance: Indications of Unidentified Moderators. Strategic Management Journal, 25, 187-200. http://dx.doi.org/10.1002/smj.371 
Kramer, M. W., Dougherty D. S., \& T. Pierce, A. (2004). Managing Uncertainty during a Corporate Acquisition: A Longitudinal Study of Communication during an Airline Acquisition. Human Communications Research, 30, 71-101. http://dx.doi.org/10.1093/hcr/30.1.71

Krug, J. A., \& Hegarty, H. W. (1997). Post-Acquisition Turnover among U.S. Top Management Teams: An Analysis of the Effects of Foreign vs. Domestic Acquisitions of U.S. Targets. Strategic Management Journal, 18 , $667-675$ http://dx.doi.org/10.1002/(SICI)1097-0266(199709)18:8<667::AID-SMJ918>3.0.CO;2-E

Larsson R. (1993). Barriers to Acculturation in Mergers and Acquisitions: Strategic Human Resource Implications. Journal of Business Education, 2, 1-18.

Larsson, R., \& Finkelstein, S. (1999). Integrating Strategic, Organizational, and Human Resource Perspectives on Mergers and Acquisitions: A Case Study of Synergy Realization. Organization Science, 10, 1-26. http://dx.doi.org/10.1287/orsc.10.1.1

Larsson, R., \& Lubatkin, M. (2001). Achieving Acculturation in Mergers and Acquisitions: An International Case Survey. Human Relations, 54, 1573-1607. http://dx.doi.org/10.1177/00187267015412002

Lee G. K., \& Lieberman M. B. (2010). Acquisition vs. internal development as modes of market entry. Strategic Management Journal, 31, 140-158. http://dx.doi.org/10.1002/smj.804

Legare T. L. (1993). The Human Side of Mergers and Acquisitions. Human Resource Management, 21, 32-41.

Lubatkin M., Calori R., Very P., \& Veiga J. F. (1998). Managing Mergers and Acquisitions across Borders: A Two-Nation Exploration of a Nationally Bound Administrative Heritage. Organization Science, 9, 670-684. http://dx.doi.org/10.1177/017084069401500303

Lubatkin, M., Schweiger, D. M., \& Weber, Y. (1999). Top Management Turnover in Related M\&A's: An Additional Test of the Theory of Relative Standing. Journal of Management, 25, 55-73. http://dx.doi.org/10.1016/S0149-2063(99)80003-8

Marks, M. L., \& Mirvis, P. H. (2001). Making mergers and acquisitions work: Strategic and psychological preparation. Academy of Management Executive, 15, 80-92. http://dx.doi.org/10.5465/AME.2001.4614947

Meschi P. X., \& Metais, E. (2006). International acquisition performance and experience: A resource-based view. Evidence from French acquisitions in the United States (1988-2004). Journal of International Management, 12, 430-448. http://dx.doi.org/10.1016/j.intman.2006.05.001

Meyer C. B., \& Altenborg, E. (2007). The Disintegrating Effects of Equality: A Study of a Failed International Merger. British Journal of Management, 18, 257-271. http://dx.doi.org/10.1111/j.1467-8551.2006.00502.x

Moeller, S. B., Schlingemann, F. P., \& Stulz, R. M. (2005). Wealth Destruction on a Massive Scale? A Study of Acquiring-Firm Returns in the Recent Merger Wave. The Journal of Finance, LX, 757-782. http://dx.doi.org/10.1111/j.1540-6261.2005.00745.x

Nahavandi A., \& Malekzadeh A. R. (1988). Acculturation in Mergers and Acquisitions. Academy of Management Review, 13, 79-90. http://dx.doi.org/10.2307/258356

Napier, N. K. (1989). Mergers and Acquisitions, Human Resources Issues and Outcomes: A Review and Suggested Typology. Journal of Management Studies, 23, 271-289. http://dx.doi.org/10.1111/j.1467-6486.1989.tb00728.x

Olie, R. (1994). Shades of culture and institutions in international mergers. Organization Studies, 37, 381-405. http://dx.doi.org/10.1177/017084069401500304

Piekkari, R., Vaara, E., Tienari, J., \& Säntti, R. (2005). Integration or Disintegration? Human Resource Implications of a Common Corporate Language Decision in a Cross-Border Merger. International Journal of Human Resource Management, 16, 330-344. http://dx.doi.org/10.1080/0958519042000339534

Ranft, A. L., \& Lord, M. D. (2002). Acquiring New Technologies and Capabilities: A Grounded Model of Acquisition Implementation. Organization Science, 13, 420-441. http://dx.doi.org/10.1287/orsc.13.4.420.2952

Rizzo J. R., J. HR., \& Lirtzman S. I. (1970). Role Conflict and Ambiguity in Complex Organizations. Administrative Science Quarterly, 15, 150-163. http://dx.doi.org/10.2307/2391486

Schein E. H. (1992). Organizational Culture and Leadership (2nd ed.). San Francisco: Jossey-Bass Publishers.

Schweiger D. M., \& Walsh J. P. (1990). Mergers and Acquisitions: An Interdisciplinary View. Greenwich, CT: 
JAI Press.

Schweiger D. M., Ivancevich J. M., \& Power F. R. (1987). Executive Actions for Managing Human Resources before and After Acquisition. Academy of Management Executive, 1, 127-138. http://dx.doi.org/10.5465/AME.1987.4275830

Schweiger, D. M., \& Denisi, A. S. (1991). Communication with Employees Following a Merger: A Longitudinal Field Experiment. Academy of Management Journal, 34, 110-135. http://dx.doi.org/10.2307/256304

Schweiger, D. M., \& Goulet, P. K. (2000). Integrating Mergers and Acquisitions: An International Research Review. In Cooper, C. L., \& Gregory, A. (Eds.), Advances in Mergers and Acqusitions (pp. 61-91). Amstedam: JAI.

Schweizer, L. (2005). Organizational Integration of Acquired Biotechnology Companies into Pharmaceutical Companies: The Need for a Hybrid Approach. Academy of Management Journal, 48, 1052-1074. http://dx.doi.org/10.5465/AMJ.2005.19573109

Seo M. G., \& Hill N. S. (2005). Understanding the Human Side of Merger and Acquisition. The Journal of Applied Behavioral Science, 41, 422-443. http://dx.doi.org/10.1177/0021886305281902

Shelton, L. M. (1988). Strategic Business Fits and Corporate Acquisition: Empirical Evidence. Strategic Management Journal, 9, 297-287. http://dx.doi.org/10.1002/smj.4250090307

Shrivastava, P. (1986). Postmerger Integration. Journal of Business Strategy, 17, 65-76. http://dx.doi.org/10.1108/eb039143

Sirower, M. L. (1997). The Synergy Trap - How Companies Lose the Acquisition Game. New York: The Free Press.

Vaara E., Tienari J., Piekkari R., \& Säntti R. (2005). Language and the Circuits of Power in a Merging Multinational Corporation. Journal of Management Studies, 42, 595-623. http://dx.doi.org/10.1080/0958519042000339534

Vaara, E. (1999). Cultural Differences and Post-Merger Problems, Misconceptions and Cognitive Simplifications. Nordic Organization Studies, 1(2), 59-88.

Vaara, E., Tienari, J., \& Säntti, R. (2003). The International Match: Metaphors as Vehicles of Social Identity-Building in Cross-Border Mergers. Human Relations, 56, 419-451. http://dx.doi.org/10.1177/0018726703056004002

Van Dick, R., Ullrich, J., \& Tissington, P. A. (2006). Working under a Black Cloud: How to Sustain Organizational Identification after a Merger. British Journal of Management, 17, 69-79. http://dx.doi.org/10.1111/j.1467-8551.2006.00479.x

Voss C., Tsikriktsis N., \& Frohlich M. (2002). Case Research in Operations Management. International Journal of Operations \& Production Management, 22, 195-219. http://dx.doi.org/10.1108/01443570210414329

Walsh, J. P. (1988). Top Management Turnover Following Mergers and Acquisitions. Strategic Management Journal, 9, 173-183. http://dx.doi.org/10.1002/smj.4250090207

Weber Y. (1996). Corporate Cultural Fit and Performance in Mergers and Acquisitions. Human Relations, 49, 1181-1202. http://dx.doi.org/10.1177/001872679604900903

Weber Y., Shenkar O., \& Raveh A. (1996). National and Corporate Cultural Fit in Mergers/Acquisitions: An Exploratory Study. Management Science, 42, 1215-1227. http://dx.doi.org/10.1287/mnsc.42.8.1215

Weber Y., Tarba S. Y., \& Reichel A. (2011). A Model of the Influence of Culture on Integration Approaches and International Mergers and Acquisitions Performance. International Studies of Management \& Organization, 41, 9-24. http://dx.doi.org/10.2753/IMO0020-8825410301

Yin, R. K. (2003). Case Study Resarch, Designs and Methods. Thousand Oaks, California: Sage Publications, Inc. 